\title{
Proceeding
}

9th INSHS International Christmas Sport Scientific Conference, 4-6 December 2014. International Network of Sport and Health

Science. Szombathely, Hungary

\section{Heart rate response to a climber's fall in sport climbing}

\section{DAVID CHALOUPSKY}

Department of Leisure and Tourism, Faculty of Informatics and Management, University of Hradec Kralove, Czech Republic

\begin{abstract}
Chaloupsky, D. (2015). Heart rate response to a climber's fall in sport climbing J. Hum. Sport Exerc., 9(Proc1), pp.S218-S226. The research deals with response of heart rate to a climber's simulated fall in a leading position when indoor climbing. Heart rate of climbers was recorded during ascents of an overhanging route in the leading position, to the given point high above the ground, followed by falling into the last protection. The length of the free fall was defined by the place of the last belay anchor, which was at the height of climber's ankles. The length of the fall was about two meters of free fall plus the consequent rope shift in dynamic belaying system. The total length of the fall was 3 to 6 meters, depending on the dynamic belaying. The sample comprised 14 participants at the age of $16-43 ; 12$ men and 2 women; all the participants were advanced climbers experienced with a fall in the position of a lead. Heart rate values observed during the fall did not significantly exceed the heart rate values during the actual climbing, when climbers usually reach $84-96 \%$ of their maximal heart rate (1 exception). The results of the analysis suggest inter-individual differences in heart rate response to the load when climbing and subsequently falling, particularly during the fall and also in the recovery of the actual fall. Key words: CLIMBING, ROCK CLIMBING, PHYSIOLOGY, FEAR, STRESS.
\end{abstract}

Corresponding author. University of Hradec Kralove, Faculty of Informatics and Management, Department of Leisure and Tourism, Czech Republic. Rokitanskeho 62, 50003

E-mail: david.chaloupsky@uhk.cz

9th INSHS International Christmas Sport Scientific Conference, 4-6 December 2014. International Network of Sport and

Health Science. Szombathely, Hungary.

JOURNAL OF HUMAN SPORT \& EXERCISE ISSN 1988-5202

(c) Faculty of Education. University of Alicante

doi:10.14198/jhse.2015.10.Proc1.09 


\section{INTRODUCTION}

The research is focused on response of heart rate to a climber's simulated fall in a leading position when indoor climbing. This paper deals with two questions: What is the heart rate reaction to a fall in rock climbing? What is the progress of heart rate due the stress during the fall and following recovery?

Climbing requires repetitive isometric contractions of forearm muscles and it can be expected that heart rate would rise rapidly per each metre of an ascent. (Sheel, 2004; Giles at al. 2006). Billat et al. (1995) found out that climbers reach about $80 \%$ of their maximal heart rate during climbing. Sheel at al. (2003) discovered that heart rate was $89 \%$ of the maximal heart rate during harder climbing and $66 \%$ during easier climbing and that the heart rate increased in dependence on climbing difficulty. Other reported values during climbing range from 129 to 180 beats per min in different studies (Billat at al., 1995; Booth at al., 1999; Watts at al., 2000; Janot at al., 2000). Mermier at al. (1997) explained the increased heart rate during climbing due to the effect of arm position because the arms are often held above the heart. This is in agreement with Astrand, Guharay and Wahren (1968) and their findings that performing arm exercises with the arms above the head is associated with bigger increase in heart rate than in exercise with the arms at the waist level.

Mermier at al. (1997) assumed that heart rate could be increased because of psychological stress or anxiety. However, Willians at al. (1978) claimed that: "...climbing represents more of anxiety type of psychological stress than a physical stress and as such is probably to increases moral fibre rather than muscle fibre."

Some researchers (Draper at al. 2008 \& 2010, de Geus at al. 2006) focused on different physiological load during different types of climbing, such as lead climbing, on sight, red point or top rope climbing. Aras and Akalan (2014) examined the effect of anxiety of falling on selected physiological aspects during lead climbing or during top rope climbing, but the heart rate of climbers during the fall was not examined.

The problem of heart rate response to a climber's fall is also related to the problem of climbers's performance in dependence on rate of risk, which was surveyed by Chaloupsky (2014) \& Chaloupsky, Komestik \& Hrusova (2011).

\section{MATERIAL AND METHODS}

\section{Participants}

The sample comprised experienced climbers. The intentional selection criteria were: previous experience with falling in a leading position and performance on sport routes at least $5+$ degree of difficulty by OS style (on sight) and at least 6- degree of difficulty by RP style (red point) of the UIAA scale of difficulty. The criteria corresponded to the difficulty of the route which climbers were to climb in the experiment.

The sample consisted of 14 participants, 12 men and 2 women, at the age of $16-43$ years. Their climbing experience was $2-24$ years. 
Table 1. Participants - basic characteristics

\begin{tabular}{c|c|c|c|c}
\hline No. & Participant & Sex & Age & Years of experience \\
\hline 1 & CH.D. & M & 43 & 24 \\
\hline 2 & V.M. & M & 21 & 2 \\
\hline 3 & S.S.. & M & 21 & 5 \\
\hline 4 & Š.K. & M & 16 & 3 \\
\hline 5 & H.V. & M & 37 & 10 \\
\hline 6 & L.K. & W & 21 & 2 \\
\hline 7 & V.M. & M & 31 & 4 \\
\hline 8 & U.V. & M & 20 & 2 \\
\hline 9 & K.P. & W & 34 & 10 \\
\hline 10 & Č.P. & M & 29 & 10 \\
\hline 11 & T.J. & M & 31 & 7 \\
\hline 12 & H.L. & M & 25 & 2 \\
\hline 13 & Š.O. & M & 17 & 2 \\
\hline 14 & K.T. & M & 17 & 2 \\
\hline
\end{tabular}

\section{Measures}

Heart rate of climbers was recorded during ascents, fall and recovery. Data were collected by the Training computer Polar RS800CX with a chest transmitter. Accuracy of heart rate monitor was $\pm 1 \%$ or $1 \mathrm{bpm}$ [beats per minute]. The time when the climber reached the points of interest [start, fall position, fall] was taken on stopwatch and then transmitted to the final graphs of heart rate records as a lap time.

\section{Procedure}

Heart rate of climbers was recorded during ascents of an overhanging route in a leading position, to the given point high above the ground, followed by falling into the last protection. All the participants climbed the same route to the given point and they were supposed to fall on the count of 10 seconds.

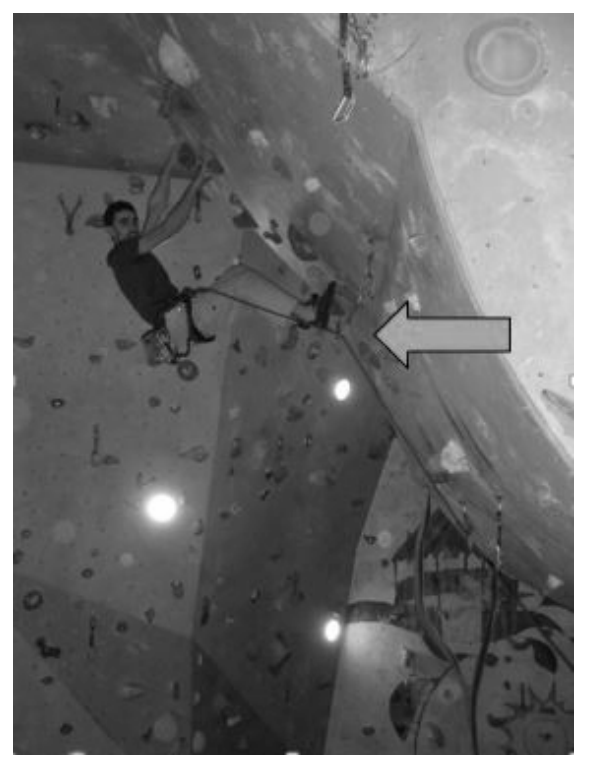

Figure 1. Climber's position before the fall 


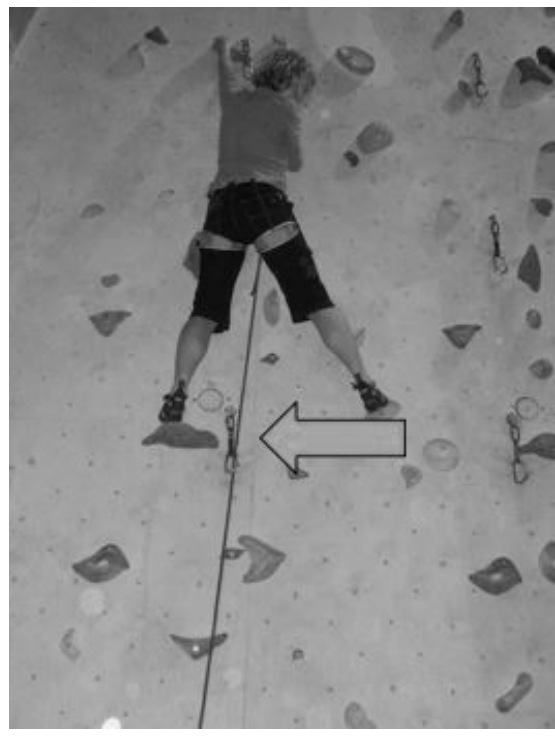

Figure 2. Position of the last protection

The last protection (belay anchor) was situated at the height of a climber's ankles.

The length of the fall was about two meters of free fall plus the consequent rope shift in dynamic belaying system.

The total length of the fall was 3 to 6 meters, depending on the dynamic belaying.

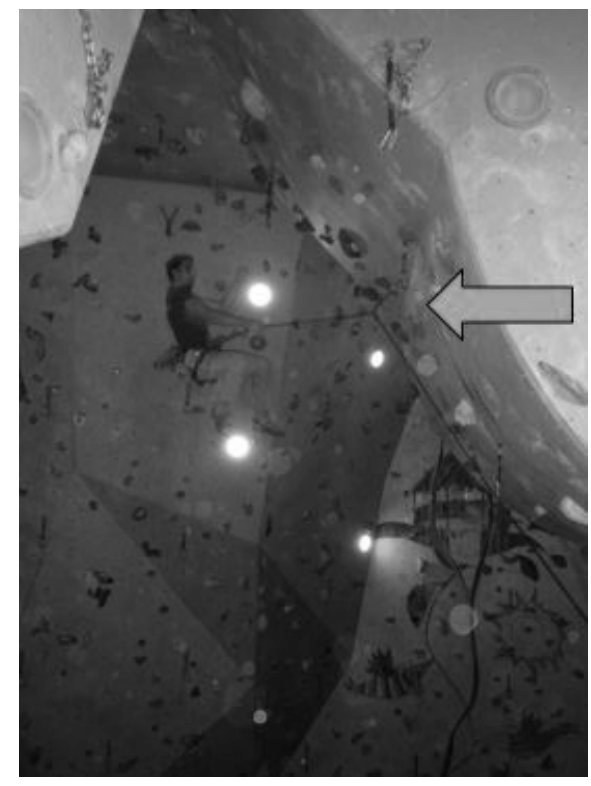

Figure 3. Climber during the fall

\section{Analysis}

Software of Polar Pro Trainer 5 was used for graphs and data analysis.

The exact points of interest, which are explained below, were entered in each graph of heart rate record. 
TOP - climber reached the end of the route to the position before the fall

JUMP - start of the fall

COOL - 10 seconds after the JUMP

The points of interest acquired in heart rate analysis:

START - heart rate at the start of climbing

Start-Top - maximal heart rate between START and TOP

Top-Jump - maximal heart rate between TOP and JUMP

HR max \% - percentage of maximal heart rate of each participant

Jump-Cool Min - minimal heart rate between JUMP and COOL

Jump-Cool Max - maximal heart rate between JUMP and COOL

Max-Min - difference of heart rate between Jump-Cool Max and Jump-Cool Min

The individual maximal heart rate was counted by formula: 220 minus age of participant.

What is the significant difference of heart rate response to a climber's fall in sport climbing?

Criterion of significant heart rate difference between Jump-Cool Max and Jump-Cool Min was determined 5 or more heart beats.

\section{RESULTS}

Table 2. Heart rate values

\begin{tabular}{c|c|c|c|c|c|c|c|c|c|c|c} 
No. & Participant & START & Start - Top & TOP & Top-Jump & JUMP & COOL & TF max \% & Jump-Cool Min & Jump-Cool Max & Max-Min \\
\hline 1 & CH.D. & 89 & 148 & 147 & 152 & 151 & 147 & $86 \%$ & 150 & 152 & 2 \\
\hline 2 & V.M. & 118 & 168 & 163 & 172 & 169 & 166 & $86 \%$ & 168 & 169 & 1 \\
\hline 3 & S.S. & 91 & 162 & 162 & 167 & 166 & 164 & $84 \%$ & 166 & 168 & 2 \\
\hline 4 & S.K. & 108 & 190 & 189 & 190 & 180 & 170 & $93 \%$ & 175 & 177 & 2 \\
\hline 5 & H.V. & 65 & 171 & 170 & 171 & 159 & 159 & $93 \%$ & 158 & 160 & 2 \\
\hline 6 & L.K. & 90 & 165 & 163 & 167 & 163 & 167 & $84 \%$ & 163 & 167 & 4 \\
\hline 7 & V.M. & 84 & 176 & 175 & 177 & 174 & 168 & $94 \%$ & 173 & 173 & 0 \\
\hline 8 & U.V. & 111 & 186 & 179 & 180 & 171 & 175 & $93 \%$ & 171 & 176 & 5 \\
\hline 9 & K.P. & 132 & 193 & 192 & 192 & 185 & 187 & $104 \%$ & 187 & 190 & 3 \\
\hline 10 & C.P. & 109 & 165 & 166 & 166 & 161 & 164 & $87 \%$ & 159 & 164 & 5 \\
\hline 11 & T.J. & 122 & 175 & 175 & 177 & 176 & 166 & $94 \%$ & 176 & 176 & 0 \\
\hline 12 & H.L. & 97 & 186 & 184 & 186 & 175 & 167 & $95 \%$ & 174 & 175 & 1 \\
\hline 13 & S.O. & 100 & 178 & 179 & 180 & 172 & 164 & $89 \%$ & 172 & 174 & 2 \\
\hline 14 & K.T. & 139 & 173 & 173 & 177 & 169 & 171 & $87 \%$ & 165 & 172 & 7 \\
\hline
\end{tabular}

The most frequent HR Max was monitored in the period of Top-Jump in 11 cases.

Only 1 climber reached the HR Max in the period of Jump-Cool and 2 climbers had the same values in different periods.

No climber had their HR Max right in the moment of the fall.

Difference between Jump-Cool Max and Jump-Cool Min bigger than 5 beats was observed only in 3 cases. In 11 cases the difference was $1-4$ beats and in 2 cases there was no difference in heart rate.

Climbers reached 84 - 96\% of their maximal heart rate (1 exception) during the experiment. 


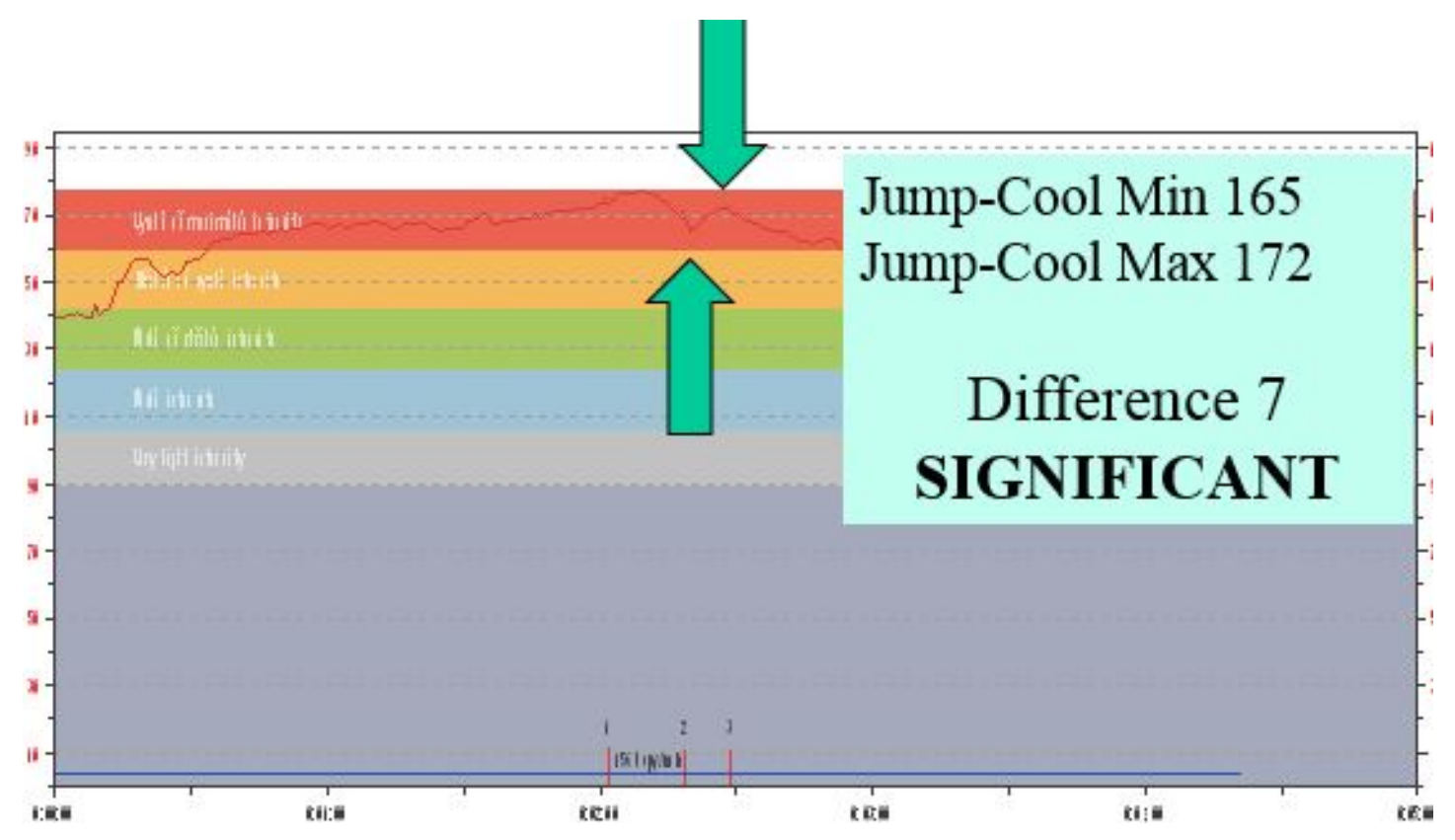

Figure 3. Example - Significant difference between Jump-Cool Max and Jump-Cool Min

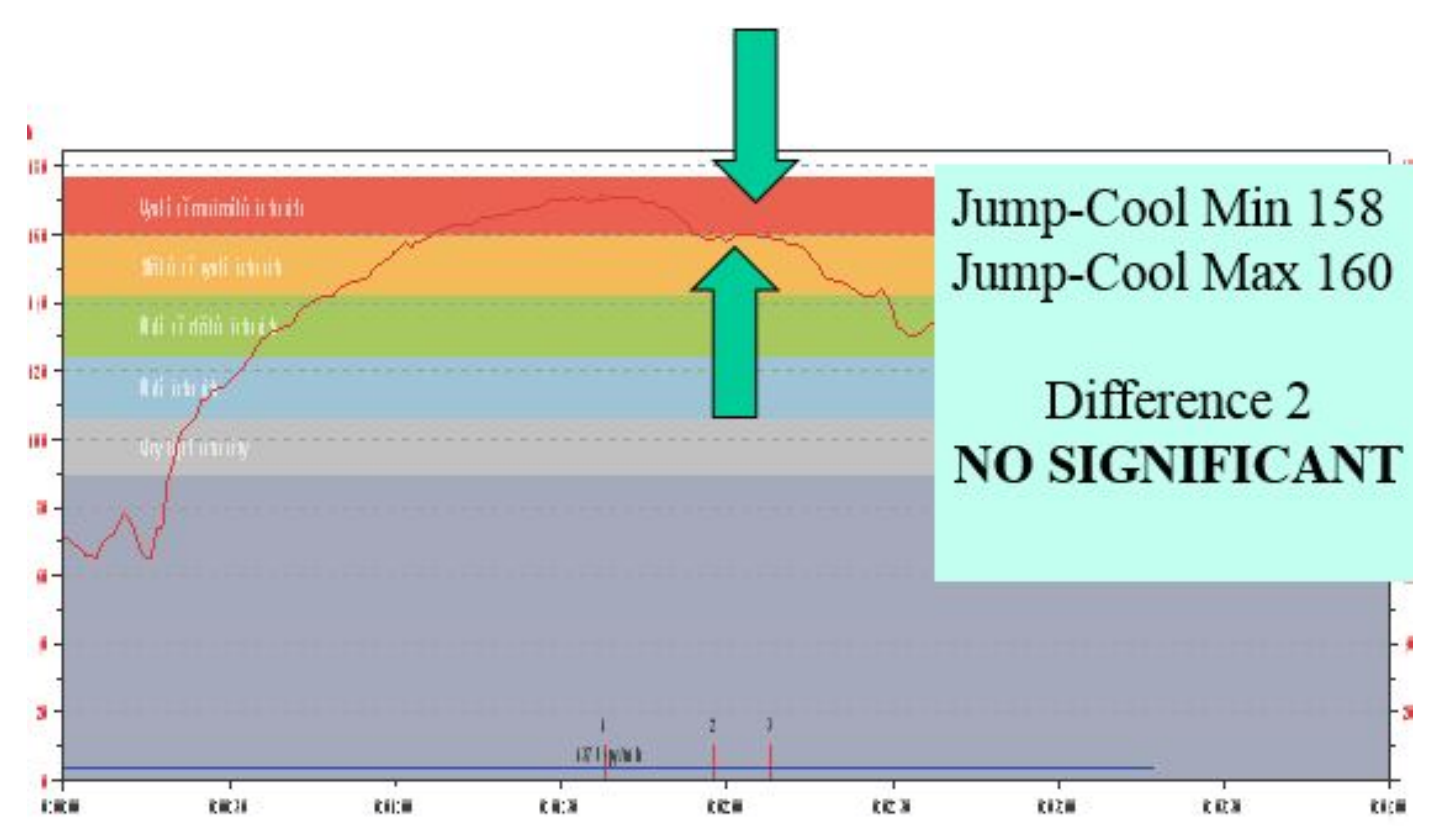

Figure 4. Example - No significant difference between Jump-Cool Max and Jump-Cool Min 


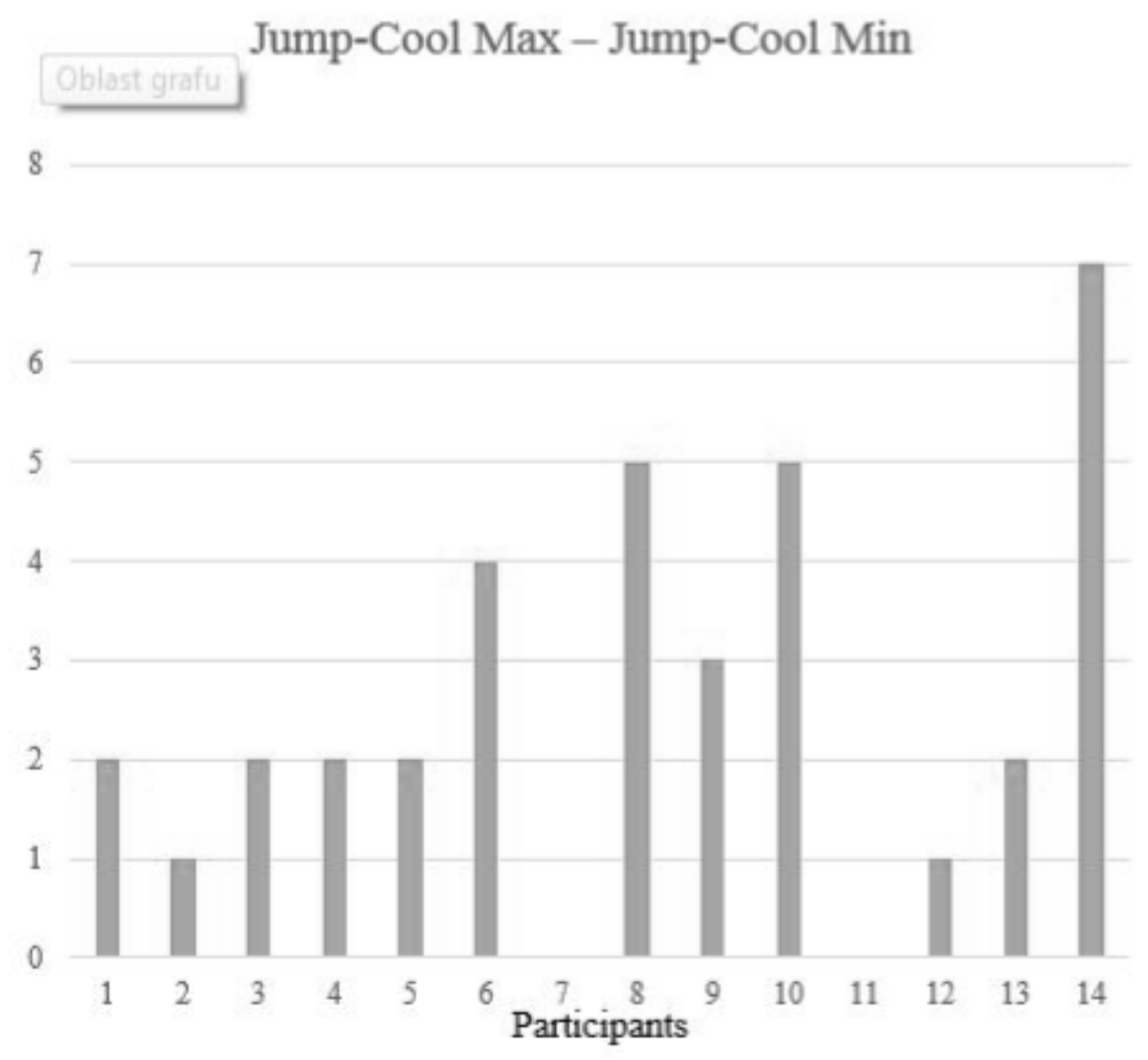

Figure 5. Heart rate difference between Jump-Cool Max and Jump-Cool Min

The determined criterion of heart rate difference 5 or more was fulfilled only in 3 out of 14 cases.

\section{DISCUSSION}

The research showed a lower heart rate reaction to the fall during rock climbing than assumed. A significant progress of heart rate due to the stress during the fall and following recovery response of heart rate was not discovered.

Assumption that the heart rate would rise rapidly during climbing was verified, which is in agreement with Sheel, 2004 \& Giles, 2006.

Climbers participating in the experiment reached $84-96 \%$ of their maximal heart rate (1 exception). Although the individual maximal heart rate is commonly counted by the given formula (220 minus age of participant) in practice it would be recommended to verify it by an exact laboratory test.

The participants in this research reached higher values compared to the studies of Billat et al. (1995) and Sheel at al. (2003). It was difficult to compare the results of this study with other reported values of heart rate response during climbing (Billat, 1995; Booth, 1999; Watts, 2000; Janot, 2000) because the authors did not refer them to the individual characteristics of the participants.

The results are not in agreement with Mermier at al. (1997) who suggested that heart rate could be increased because of psychological stress or anxiety. The findings do not correspond to Willians at al. 
(1972) who claimed that: "...climbing represents more of anxiety type of psychological stress than a physical stress and as such is probably to increases moral fibre rather than muscle fibre." The climbers reached high values of heart rate due to the difficulty of climbing rather than the anxiety of fall.

It should be pointed out that climbers reached a high level of individual heart rate during climbing close to their maximal heart rate and thus there was little space for further increase during the fall and recovery.

The results of the analysis suggested inter-individual differences in heart rate response to the load when climbing and subsequently falling, particularly during the fall and also in the recovery of the actual fall. This is supported by the findings of Chaloupsky (2014) that each climber has different level of acceptable risktaking.

\section{CONCLUSIONS}

Heart rate values observed during the fall did not significantly exceed the heart rate values during the actual climbing.

There was no significant progress of heart rate due the stress during the fall and following recovery.

\section{REFERENCES}

1. Aras, D., \& Akalan, C. (2014). The effect of anxiety about falling on selected physiological parameters with different rope protocols in sport rock climbing. J Sports Med Phys Fitness, 54(1), pp.1-8.

2. Astrand, I., Guharay, A., \& Wahren J. (1968). Circulatory responses to arm exercise with different arm positions. J Appl Psychol, 25, pp.528-532.

3. Billat, V., Palleja, P., Charlaix, T., Rizzardo, P., \& Janel, N. (1995). Energy specificity of rock climbing and aerobic capacity in competitive sport rock climbers. J Sports Med Phys Fitness, 35(1), pp.20-24.

4. Booth, J., Marino, F., Hill, C., \& Gwinn, T. et al. (1999). Energy cost of sport rock climbing in elite performers. Br J Sports Med, 33, pp.14-18.

5. Chaloupsky, D. (2014). The acceptable level of risk-taking for traditional rock climbers. J. Hum. Sport Exerc, 9 (Proc1), pp.S263-S269.

6. Chaloupsky, D., Komestik, B., Hrusova, D. (2011). The Impact of the Specific Conditions of Sandstone Rock Climbing on Climber's Performance. In: Manufacturing, commerce, tourism and services (ICM-CTS '11). Athens: World scientific and engineering academy and society, pp.34-38. ISBN 978-1-61804-003-9.

7. de Geus, B., Villanueva O'Driscoll, S., \& Meeusen, R. (2006). Influence of climbing style on physiological responses during indoor rock climbing on routes with the same difficulty. European Journal of Applied Physiology, 98, pp.489-496.

8. Draper, N., Jones, G. A., Fryer, S., Hodgson, C. I., \& Blackwell, G. (2010). Physiological and psychological responses to lead and top rope climbing for intermediate rock climbers. European Journal of Sport Science, 10(1), pp.13-20.

9. Draper, N., Jones, G. A., Fryer, S., Hodgson, C., \& Blackwell, G. (2008). Effect of an on-sight lead on the physiological and psychological responses to rock climbing. Journal of Sports Science and Medicine, 7, pp.492-498. 
10. Giles, L. V., Rhodes, E. C., \& Taunton, J. E. (2006). The physiology of rock climbing. Sports Medicine, 36, pp.529-545.

11. Janot, J. M., Steffen, J. P., Porcari, J. P., \& Maher, M. A. (2000). Heart rate responses and perceived exertion for beginner and recreational sport climbers during indoor climbing. Journal of Exercise Physiology, 3(1), pp.1-7.

12. Mermier, C. M., Robergs, R. A., McMinn, S. M., \& Heyward, V. H. (1997). Energy expenditure and physiological responses during indoor rock climbing. Brit J Sport Med, 31, pp.224-228.

13. Sheel, A. W. (2004). Physiology of sport rock climbing. Brit J Sport Med, 38, pp.355-359.

14. Sheel, A. W., Seddon, N., Knight, A., McKenzie, D. C., \& Warburton, D. E. R. (2003). Physiological responses to indoor rock-climbing and their relationship to maximal cycle ergometry. Med Sci Sports Exer, 35, pp.1225-1231.

15. Watts, P. B., Daggett, M., Gallagher, P., \& Wilkins B. (2000). Metabolic response during sport rock climbing and the effects of active versus passive recovery. Int J Sports Med, 21(3), pp.185-190.

16. Williams, E. S., Taggart, P., \& Carruthers, M. (1978). Rock climbing: Observations on heart rate and plasma catecholamine concentrations and the influence of oxprenolol. Br J Sports Med, 12, pp.125-128. 